\title{
Self-monitoring of blood glucose during pregnancy: indications and limitations
}

\author{
Carlos Antonio Negrato ${ }^{1}$ and Lenita Zajdenverg ${ }^{2^{*}}$
}

\begin{abstract}
Self-monitoring of blood glucose (SMBG) is an important tool to treat diabetes during pregnancy. However, proper implementation of SMBG in pregnant women requires understanding of its applications and limitations. This article reviews issues related to the implementation, efficacy, and accuracy of SMBG and discusses factors that can confound results of SMBG during pregnancy.
\end{abstract}

Keywords: Self-monitoring of blood glucose, Diabetes mellitus, Pregnancy, Review

\section{Introduction}

Perinatal morbidity and mortality rates, often affected by maternal diabetes, have dramatically been reduced since the discovery of insulin and its therapeutic implementation. In addition to increased availability of insulin, many important technological advances have been developed over the preceding decades. These advances culminated in a larger array of diagnostic and therapeutic capabilities that contributed to improved outcomes in high-risk pregnancies.

The availability of glucose meters has represented an important positive impact in the treatment of pregnant women with any type of diabetes. Data frequently show patients who perform self-monitoring of blood glucose (SMBG) more strictly adhere to treatment programs due to increased comprehension regarding treatment and participation in the prescribed treatment regimen [1].

\section{Indications for self-monitoring of blood glucose during pregnancy complicated by diabetes}

SMBG is an integral part of standard diabetes care [2]. It allows pregnant women and their healthcare providers to determine the most effective therapeutic modality (e.g. diet, physical activity, or insulin) to control glucose levels and reduce risks of diabetes-related complications. The number of daily tests required to adequately monitor blood glucose levels is specific to the patient and based on the recommendation of the

\footnotetext{
*Correspondence: lenitazaj@gmail.com

${ }^{2}$ Nutrology and Diabetes Unit, Universidade Federal do Rio de Janeiro, Rio de Janeiro, RJ, Brazil

Full list of author information is available at the end of the article
}

practitioner [3]. Several characteristics, unique to each pregnant woman should be considered. For example, the type of treatment (diet and/or insulin), frequency and intensity of physical activity, and the risk of hypoglycemia. Additionally, SMBG makes patients feel more secure and comfortable using insulin since it allows early recognition of symptoms of hypoglycemia [4].

The indications for, and frequency of SMBG in pregnant women that are not under insulin treatment must be tailored to the individual. Patients must be trained to adjust the amount of food intake with the frequency, intensity, and timing of physical exercise. It is unclear whether SMBG alone leads to improved glycemic control in non-insulin treated subjects with type 2 diabetes. Additionally, there is no data in women with gestational diabetes mellitus (GDM) [5].

Measured glucose values need to be frequently checked to ensure both accuracy and the patient's understanding of any alterations to prescribed treatment. For the vast majority of patients using insulin, SMBG is recommended three or more times per day. A more intensive SMBG regimen is indicated for women with pre-gestational type 1 or 2 diabetes. The aim is to reach adequate HbA1c levels safely without inducing hypoglycemia [3,4].

\section{When to monitor}

Strict monitoring of postprandial glucose levels is paramount during pregnancy. Many studies have shown that postprandial hyperglycemia beyond the 16th week of pregnancy is the main predictor for fetal macrosomia $[6,7]$. Peak plasma glucose levels during pregnancy occur

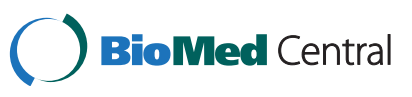


between 60 and 90 minutes after eating. It is recommended to perform SMBG one hour after food intake to evaluate potential adjustments in meal composition and/or in the prandial insulin dose. In special circumstances, like women with slowed gastric emptying, a highfat meal, or women who use regular insulin for a prandial bolus, it might be more appropriate to perform SMBG two hours after meals instead of one. SMBG performed before eating is the most useful parameter to identify optimal basal insulin doses. Evaluating glycemic levels during the night is recommended to diagnose and prevent nocturnal hypoglycemia [8].

One randomized study [6] of 66 women with GDM observed better neonatal outcomes by aiming for 1-hour postprandial glucose levels less than $140 \mathrm{mg} / \mathrm{dL}$ as opposed to a preprandial target of 59 to $106 \mathrm{mg} / \mathrm{dL}$. In another study, 61 women with type 1 diabetes were randomly assigned into two groups at 16 weeks gestation. Women either monitored blood glucose levels preprandially or postprandially. Postprandial capillary blood glucose monitoring significantly reduced the incidence of preeclampsia and neonatal triceps skinfold thickness compared to preprandial monitoring [9]. These studies have been criticized for not using comparable target blood glucose levels for pre- and post-prandial monitoring. Regardless, most specialists prefer postprandial testing at least partly, for the physiologic changes discussed earlier.

\section{Meter considerations}

Diabetes education is paramount for proper use of glucose meters and interpretation of measurements. Commercially available glucose meters vary widely with respect to several characteristics, such as: blood sample volume, size, testing speed, memory capacity, type of technology applied, costs, and type of strips used [10]. All disposable blood glucose meters function by one of two mechanisms: reflectance (photometric) or electrochemical (amperometric). Meters using reflectance measure a change in color on the strip that occurs after an enzymatic reaction with whole blood. Meters using electrochemical mechanisms work with small volumes of blood to measure electrochemical potential based on glucose oxidation [11].

\section{Issues related to self-blood glucose monitoring during pregnancy complicated by diabetes \\ Accuracy}

Accuracy of a blood glucose meter reflects how closely the measured value is to the actual value, while precision describes the reproducibility of serial measurements and is independent of the accuracy. For effective SMBG, it is imperative that meters be both accurate and precise in a series of values [12]. The best single measure of both accuracy and precision is the mean absolute relative error (MARE). MARE is calculated by taking the average for the set of individual absolute errors relative to a reference value. For example, measured values of both 90 and $110 \mathrm{mg} / \mathrm{dl}$ are in error by $10 \%$ given a reference value of $100 \mathrm{mg} / \mathrm{dl}$ [12].

The International Standards Organization (ISO), in conjunction with international regulatory authorities, healthcare providers, and device manufacturers, established standards to evaluate accuracy of blood glucose meters. ISO 15197 calls for a minimum accuracy where $95 \%$ of all measured values fall within $20 \%$ of reference values above $75 \mathrm{mg} / \mathrm{dl}$, and within $15 \mathrm{mg}$ of glucose values below $75 \mathrm{mg} / \mathrm{dl}$ [13]. According to the American Diabetes Association, 5\% of the values for glucose performed with a given glucose meter should fall below $75 \mathrm{mg} / \mathrm{dl}$ for this meter be considered accurate. According to data currently available, the most accurate meter today has only $63 \%$ acceptable values in the $5 \%$ inaccuracy range [12]. Accordingly, it can be difficult for health care providers and patients to assess the accuracy of blood glucose monitoring systems. SMBG often presents significant errors that are generally poorly understood by patients and providers [14]. Healthcare providers can help patients to obtain better results by identifying the source of errors and methods for prevention and correction [12].

\section{Inaccuracy of self-monitoring blood glucose during pregnancy complicated by diabetes}

The inaccuracy of SBGM during pregnancy comes from four sources: strip factors, physical factors, patient factors, and pharmacological factors.

\section{Strip factors}

Small strip-to-strip variation may lead to inaccuracy in blood glucose readings. In some types of glucose strips, the size of individual reaction wells and changes in enzyme coverage on the strips may influence reading accuracy [12]. Reduction of the mediator can cause problems with the accuracy of electrochemical measurements. Normally, glucose is oxidized by glucose oxidase to form gluconic acid. The reduced form of glucose oxidase then interacts with water and oxygen to form hydrogen peroxide. On a strip, the first step is identical, but in the second step, the glucose oxidase pushes electrons to the oxidized mediator, causing its reduction, rather than oxygen plus water, forming hydrogen peroxide. The electrode oxidizes the mediator, generating the glucose signal [12].

The oxidized mediator is somewhat unstable and susceptible to reduction, particularly at high temperatures, which produces erroneously high blood glucose measurements [15]. Blood glucose strips require complex biochemical reactions to function properly, and have finite lifetimes, usually about 2 years under ideal storage conditions. Storing strips at high temperature or humidity, or in an open vial (allowing the humidity to get to 
the strips) can shorten the lifetime of the strips. Different brands of glucose strips fail differently. When a failure occurs, some brands underestimate the glucose values, whereas others overestimate. In both cases, the error can be large, and usually meters are unable to detect failed strips [12].

\section{Physical factors}

The most common physical factors that influence the accuracy of blood glucose strips are altitude and temperature [12].

Glucose oxidase biosensor strips are sensitive to oxygen concentrations. The mediator and oxygen can both compete as oxidants of the reduced form of glucose oxidase. Since the electrode will only detect the mediator, excess oxygen robs electrons from the active mediator leading to underestimated glucose values. Conversely, at lower oxygen concentrations, meters will overestimate blood glucose levels. Consequently, glucose oxidase biosensor strips are generally calibrated with capillary blood and are most accurate when used with capillary blood. Strips that use glucose dehydrogenase as the enzyme are less affected by oxygen, and therefore are less affected by altitude [12].

The influence of temperature is less predictable. Errors presented at extreme temperatures are brand-specific and not technology dependent. The errors may vary from $5-7 \%$, but can be either positive or negative [12]. Low temperatures decrease circulation to the skin. This does not greatly influence glucose measured from a fingertip since the arteriovenous shunts of the fingers stay open. However, blood flow to the skin of the forearm is dramatically decreased. Alternative site testing, which normally has a lag of 15-30 min, can have a lag of up to an hour when the arm is exposed to a very low temperature [16].

\section{Patient factors}

The ability of a patient to use her meter properly can greatly influence the accuracy of a blood glucose measurement. Most blood glucose meters need to be coded. Coding determines the relationship between the electrical signal produced by the strip and the reported blood glucose. Improper coding is one of the most common mistakes made by patients and the effect of miscoding is not uniform across all blood glucose ranges [12]. Meters that do not require coding are more readily available and are more accurate when used by patients.

Hematocrit abnormalities can also affect the results obtained from SMBG. Hematocrit less than 30\% may overestimate blood glucose, while hematocrit greater than 55\% may underestimate measurements [17]. All meters use whole blood concentration from capillaries. When venous blood collected in laboratories, blood glucose is measured with respect to plasma and not whole blood. The density of erythrocytes causes glucose content to be $10 \%$ to $15 \%$ lower in whole blood than in plasma. However, most new meters convert whole-blood results into plasma-calibrated results [10].

Plasma glucose levels in individuals with normal hematocrit is $11 \%$ higher than in whole blood (venous or capillary). The International Federation of Clinical Chemistry and Laboratory Medicine (IFCC) recommends expressing plasma glucose values rather than whole blood values. Expression of plasma glucose values facilitates comparison with measurements obtained by laboratories. Plasma values can be obtained by multiplying whole blood glucose concentration by 1.1. Many glucose meters already convert blood values to plasma values. The glucose meter manufacturer should expressly state whether a meter automatically converts the whole blood measurement to a plasma measurement.

SMBG devices are frequently updating styles, models, and technologies. Systems are becoming more accurate and easier for patients to use appropriately. Hand washing has always been problematic, but because many newer meters use microsamples, small amounts of contaminant can greatly alter results [12]. Some substances that occur naturally in the body can affect the accuracy of electrochemical blood glucose meters. These include triglycerides, oxygen, and uric acid. High levels of triglycerides cause underestimation of blood glucose by displacing glucose in the capillary volume. Many pregnant women present with high triglycerides levels, especially in the third trimester, and this could lead to inaccuracy in their SMBG values. Oxygen competes with the mediator to take electrons from reduced glucose oxidase and high oxygen values, such as those found in arterial blood or in patients utilizing oxygen, will underestimate glucose values $[12,18]$. Low oxygen levels, in venous blood or patients with severe chronic obstructive pulmonary disease may overestimate glucose values. Extremely high levels of uric acid can give incorrectly high values. Uric acid is only problematic in patients with uric acid levels that are sufficient to induce severe gout [12,19].

Glucose dehydrogenase is a less specific enzyme, so some naturally occurring sugars can compete with glucose. Galactose, xylose, and maltose compete with glucose for glucose dehydrogenase binding sites and high levels of these other sugars can cause overestimations of glucose levels. However, glucose dehydrogenase sensors are less sensitive to variations in oxygen concentration [20].

\section{Pharmacologic factors}

Many medications can affect the readings from SMBG. With electrochemical glucose oxidase systems, acetaminophen, L-dopa, tolazamide, and ascorbic acid interact with the electrode [19]. Fortunately, the error from these 
medications is usually small. With glucose dehydrogenase, many other sugars can interfere. Maltose and xylose can have a small effect, but icodextrin can have a tremendous effect [21]. Icodextrin is used in some peritoneal dialysis fluids and can increase glucose value reported by the meter by more than $100 \mathrm{mg} / \mathrm{dl}$. Meter manufacturers generally do not disclose what substances interfere with their specific product. However, doing so when possible would improve accuracy of SMBG measurements by patients and ultimate therapeutic efficacy.

\section{Barriers to self-monitoring of blood glucose during pregnancy}

The first step towards a successful SMBG during pregnancy is patient education and an understanding of the importance of SMBG to reducing complications during and after pregnancy. The patient must be properly educated on all aspects of meter use. It is important she be aware of how to properly code her meter, wash her hands prior to the test, and to apply the correct amount of blood to the test strip. It is also critical to educate patients on how glucose from food can affect the test results, to use test strips before the expiration date and not longer than 90 days after the vial was opened. Lastly, it is crucial to educate patients on proper storage of strips and disposal of strips if they are subjected to extreme humidity or temperature. Other common barriers to SMBG include costs of the meters and strips, lower socio-economic status, fewer $\mathrm{HbA} 1 \mathrm{c}$ tests, obesity and other comorbidities, poor glycemic control, stigmas of testing in public places, pain, and inconvenience [4,22].

During pregnancy, relatively small changes in glucose values may be clinically important. In clinical practice, it is important to know how closely the glucose meter readings can reflect the patient's real plasma glucose level. Perera et al. recently showed differences of up to $15 \%$ between SMBG and plasma glucose values. Variations of up to $15 \mathrm{mg} / \mathrm{dl}$ were found in pregnant women with diabetes [23]. On the other hand, Kong et al. found correlation between the SMBG and plasma glucose levels in $90 \%$ of the measurements performed in women with GDM that reached normoglycemia after dietary treatment exclusively [24].

\section{Conclusions}

Treating hyperglycemia during pregnancy reduces adverse pregnancy outcomes. The first step towards a tight glucose control in pregnancy is patient adherence to SMBG. There are several barriers and sources of errors associated with SMBG. Pregnancy is a unique short period of time when physicians, diabetes educators, and healthcare professionals in general have the chance to provide information and education about diabetes and SMBG. Specifically, it is an opportunity to educate women on error prevention and correct interpretation of results. Additionally, they can provide assistance to overcome barriers associated with proper diabetes care and provide long-lasting benefits to the mother and fetus.

\section{Competing interests}

Authors do not have any competing interests (financial, political, personal, religious, ideological, academic, intellectual, commercial or any other) to declare in relation to this manuscript.

\section{Authors' contributions}

CAN and LZ participated in article design and coordination and helped to draft the manuscript. All authors read and approved the final manuscript

\section{Author details}

${ }^{1}$ Gestational Diabetes Department of the Brazilian Diabetes Society, São Paulo, SP, Brazil. ${ }^{2}$ Nutrology and Diabetes Unit, Universidade Federal do Rio de Janeiro, Rio de Janeiro, RJ, Brazil.

Received: 26 July 2012 Accepted: 15 December 2012

Published: 22 December 2012

\section{References}

1. Karter AJ, Ackerson LM, Darbinian JA, D'Agostino RB Jr, Ferrara A, Liu J, Selby JV: Self-monitoring of blood glucose levels and glycemic control: the Northern California kaiser permanente diabetes registry. Am J Med 2001, 111(1):1-9.

2. Bergenstal RM, Gavin JR III: Global consensus conference on glucose monitoring panel. the role of self-monitoring of blood glucose in the care of people with diabetes: report of a global consensus conference. Am J Med 2005, 118(9A):1S-6S.

3. National Diabetes Information Clearing House: A Service of National Institute of Diabetes and Digestive and Kidney Disease. National Diabetes Statistics; 2003 [http://diabetes.niddk.nih.gov/dm/pubs/statistics].

4. American Diabetes Association: Testing of glycemia in diabetes. Diabetes Care 2003, 26:S106-\$108

5. Welschen LM, Bloemendal E, Nijpels G, Dekker JM, Heine RJ, Stalman WA, Bouter LM: Self-monitoring of blood glucose in patients with type 2 diabetes who are not using insulin: a systematic review. Diabetes Care 2005, 28:1510-1517.

6. de Veciana M, Major CA, Morgan MA, Asrat T, Toohey JS, Lien JM, Evans AT: Postprandial versus preprandial blood glucose monitoring in women with gestational diabetes mellitus requiring insulin therapy. $N$ Engl J Med 1995, 333:1237-1241

7. Bühling KJ, Winkel T, Wolf C, Kurzidim B, Mahmoudi M, Wohlfarth K, Wäscher C, Schink T, Dudenhausen JW: Optimal timing for postprandial glucose measurement in pregnant women with diabetes and a nondiabetic pregnant population evaluated by the continuous glucose monitoring system (CGMS). J Perinat Med 2005, 33(2):125-131.

8. Negrato CA, Montenegro RM Jr, Mattar R, Zajdenverg L, Francisco RP, Pereira BG, Sancovski M, Torloni MR, Dib SA, Viggiano CE, Golbert A, Moisés EC, Favaro MI, Calderon IM, Fusaro S, Piliakas VD, Dias JP, Gomes MB, Jovanovic L: Dysglycemias in pregnancy: from diagnosis to treatment. Brazilian consensus statement. Diabetol Metab Syndr 2010, 2:27.

9. Manderson JG, Patterson CC, Hadden DR, Traub Al, Ennis C, McCance DR: Preprandial versus postprandial blood glucose monitoring in type 1 diabetic pregnancy: a randomized controlled clinical trial. Am J Obstet Gynecol 2003, 189(2):507-512

10. Briggs $L A$, Cornell S: Self-monitoring blood glucose (SMBG): now and the future. J Pharm Pract 2004, 17(1):29-38.

11. Cornell S: Self-monitoring blood glucose monitor update. Adv Pharm 2003, 1:106-111.

12. Ginsberg BH: Factors affecting blood glucose monitoring: sources of errors in measurement. J Diabetes Sci Technol 2009, 3(4):903-913.

13. International Organization for Standardization: In vitro diagnostic test systems Requirements for blood-glucose monitoring system for self-testing in managing diabetes mellitus, Reference number ISO 15197. Geneva: International Organization for Standardization; 2003. http://www.iso.org/iso/ home/store/catalogue_tc/catalogue_detail.htm?csnumber=26309. 
14. Hirsch IB, Bode BW, Childs BP, Close KL, Fisher WA, Gavin JR, Ginsberg BH, Raine $\mathrm{CH}$, Verderese CA: Self-monitoring of blood glucose (SMBG) in insulin- and non-insulin-using adults with diabetes: consensus recommendations for improving SMBG accuracy, utilization, and research. Diabetes Technol Ther 2008, 10(6):419-439.

15. Bamberg R, Schulman K, MacKenzie M, Moore J, Olchesky S: Effect of adverse storage conditions on performance of glucometer test strips. Clin Lab Sci 2005, 18(4):203-209.

16. Haupt A, Berg B, Paschen P, Dreyer M, Häring HU, Smedegaard J, Matthaei S: The effects of skin temperature and testing site on blood glucose measurements taken by a modern blood glucose monitoring device. Diabetes Technol Ther 2005, 7(4):597-601.

17. LifeScan I: Frequently asked questions about alternative site testing. Life Scan report AW0507-633. Milpitas. CA: LifeScan, Inc; 2002.

18. Ervin KR, Kiser EJ: Issues and implications in the selection of blood glucose monitoring technologies. Diabetes Technol Ther 1999, 1(1):3-11.

19. Kost GJ, Vu HT, Lee JH, Bourgeois P, Kiechle FL, Martin C, Miller SS, Okorodudu AO, Podczasy JJ, Webster R, Whitlow KJ: Multicenter study of oxygen-insensitive handheld glucose point-of-care testing in critical care/hospital/ambulatory patients in the United States and Canada. Crit Care Med 1998, 26(3):581-590.

20. Bishop ML, Fody EP, Schoeff LE: Clinical chemistry: principles, procedures, correlations. 5th edition. Baltimore: Lippincott Williams \& Wilkins; 2005:275.

21. Schleis TG: Interference of maltose, icodextrin, galactose, or xylose with some blood glucose monitoring systems. Pharmacotherapy 2007, 27(9):1313-1321.

22. Adams AS, Mah G, Soumerai SB, Zhang F, Barton MB, Ross-Degnan D: Barriers to self-monitoring of blood glucose among adults with diabetes in HMO: a cross sectional study. BMC Health Serv Res 2003, 3(1):6.

23. Perera NJ, Molyneaux L, Constantino MI, McGill M, Yue DK, Twigg SM, Ross GP: Suboptimal performance of blood glucose meters in an antenatal diabetes clinic. Diabetes Care 2011, 34:335-337.

24. Kong GWS, Tam WH, Chan MHM, So WY, Lam CWK, Yiu IPC, Loo KM, Li CY: Comparison in the performance of glucose meters in blood glucose monitoring during pregnancy. Gynecol Obstet Invest 2010, 69:264-269.

doi:10.1186/1758-5996-4-54

Cite this article as: Negrato and Zajdenverg: Self-monitoring of blood glucose during pregnancy: indications and limitations. Diabetology \& Metabolic Syndrome 2012 4:54.

\section{Submit your next manuscript to BioMed Central and take full advantage of:}

- Convenient online submission

- Thorough peer review

- No space constraints or color figure charges

- Immediate publication on acceptance

- Inclusion in PubMed, CAS, Scopus and Google Scholar

- Research which is freely available for redistribution

Submit your manuscript at www.biomedcentral.com/submit
(O) Biomed Central 